\title{
Membrane Stabilizing and Cytotoxic Activities of Different Kupchan Partitionates of Oroxylum indicum (L.) Vent. Leaf and Bark Extracts
}

\author{
Ketoki Chakma ${ }^{1}$, Fahima Aktar², Md. Ruhul Kuddus², Shaila Kabir ${ }^{2}$ \\ and Mohammad A. Rashid ${ }^{2}$ \\ ${ }^{1}$ Department of Pharmacy, State University of Bangladesh, 77 Satmosjid Road \\ Dhanmondi, Dhaka-1207, Bangladesh \\ ${ }^{2}$ Phytochemical Research Laboratory, Department of Pharmaceutical Chemistry, Faculty of Pharmacy \\ University of Dhaka, Dhaka-1000, Bangladesh
}

The methanol extract of the leaf and bark of Oroxylum indicum (L.) Vent. and their different organic soluble partitionates were screened for membrane stabilizing and cytotoxic activities. Among all samples, the chloroform soluble fraction of crude methanol extract of leaf of $O$. indicum exhibited highest inhibition of haemolysis of RBC (72.22\%) as compared to $82.22 \%$, exerted by the standard acetyl salicylic acid $(0.10 \mathrm{mg} / \mathrm{ml})$. In brine shrimp lethality assay, the petroleum-ether soluble fraction of crude methanol extract of leaf and carbon tetrachloride soluble fraction of bark demonstrated strong cytotoxic activity with $\mathrm{LC}_{50}$ value of 1.81 and $6.54 \mu \mathrm{g} / \mathrm{ml}$, respectively, while standard vincristine sulphate produced $\mathrm{LC}_{50}$ of $0.451 \mu \mathrm{g} / \mathrm{ml}$.

O. indicum (Family Bignoniaceae) is a medium sized deciduous evergreen tree upto $12 \mathrm{~m}$ high that is distributed throughout the hilly areas of Bangladesh, Assam, Malacca, Srilanka, Malay Islands and China. It is also known as shoyanka, sonpatha or midnight horror. ${ }^{1}$ The plant is reported to possess antiinflammatory, diuretic, anti-arthritic, antifungal and antibacterial activities. ${ }^{2}$ The decoction of bark can be used as a potent anticancer medicine, especially against nasopharyngeal carcinoma. ${ }^{3,4}$ The plant contains plant contains flavonoids like chrysin, oroxylin and baicalein as active principles. ${ }^{5}$ Leaves are emollient,

Correspondence to: Mohammad A. Rashid Tel.: 880-2-9661900-73, Extn. 8137; Fax: 880-2-8615583; E-mail: rashidma@du.ac.bd

Dhaka Univ. J. Pharm. Sci. 12(2): 181-183, 2013 (December) that contain anthraquinone and aloe-emodin. ${ }^{6}$ Phytochemicals like flavonoids and phenolic acids, commonly found in plants have been reported to exhibit multiple biological effects, including antioxidant properties. ${ }^{7}$ Therefore, medicinal plants can be a potential source of natural antioxidants. ${ }^{8}$

As part of our ongoing research with medicinal plant of Bangladesh ${ }^{9-10}$ the present study has been undertaken to evaluate the membrane stabilizing and cytotoxic activities of $O$. indicum leaf and bark extracts as well as to find out the logical evidence for folkloric uses of this plant.

The leaf and bark of the plant were collected from Khagrachari district in 2010. A voucher specimen for this plant has been maintained in Bangladesh National Herbarium, Dhaka, Bangladesh for future reference. The bark was cut into small pieces and both bark and leaves were sun dried for 7 days followed by oven drying for 24 hours at $40{ }^{\circ} \mathrm{C}$ to facilitate proper grinding.

The powdered materials (500 g of each for leaf and bark) were separately soaked in $1.5 \mathrm{~L}$ of methanol in a large conical flask for 7 days with occasional shaking and stirring. The whole mixture was then filtered off through a cotton plug followed by Whatman filter paper no. 1 and the filtrate thus obtained was concentrated with the help of a rotary evaporator. An aliquot (5.0 g) of the concentrated methanol extract of both samples was separately fractionated by the modified Kupchan partitioning protocol $^{11}$ which afforded petroleum-ether (450.0 
mg), carbon tetrachloride (900.0 mg), chloroform (550.0 mg) and aqueous (2.5 g) soluble materials from the crude methanolic extract of leaf while the bark extract provided petroleum-ether (350.0 mg), carbon tetrachloride (480.0 mg), chloroform (530.0 $\mathrm{mg}$ ) and aqueous (1.6 g) soluble materials.

The membrane stabilizing activity was determined by using hypotonic solution induced hemolysis of mice erythrocyte. ${ }^{12}$ The percentage inhibition of either hemolysis or membrane stabilization was calculated by using the following equation-

$\%$ inhibition of hemolysis $=100 \times\left(\mathrm{OD}_{1}-\mathrm{OD}_{2} / \mathrm{OD}_{1}\right)$ where, $\mathrm{OD}_{1}=$ optical density of hypotonic-buffered saline solution alone (control) and $\mathrm{OD}_{2}=$ optical density of test sample in hypotonic solution.

Brine shrimp lethality bioassay ${ }^{13}$ is a rapid and comprehensive bioassay for bioactive compounds of natural and synthetic origins. By this method, natural product extracts, fractions as well as the pure compounds can be tested for their bioactivities. This technique was applied for determination of the general toxic property of the plant extractives.

The extractives at concentration $2.0 \mathrm{mg} / \mathrm{ml}$ significantly protected the lysis of human erythrocyte membrane induced by hypotonic solution, as compared to the standard acetyl salicylic acid $(0.10$ $\mathrm{mg} / \mathrm{ml}$ ) (Table-1). Among all extractives, the chloroform soluble fraction of crude methanol extract of leaf produced highest $72.22 \%$ inhibition of haemolysis of RBC while the crude extracts and their petroleum ether and aqueous soluble fraction produced $67.77 \%, 66.66 \%$, and $67.89 \%$ inhibition of haemolysis of RBC, respectively as compared to $82.22 \%$, produced by acetyl salicylic acid $(0.10$ $\mathrm{mg} / \mathrm{mL}$ ). The other test samples of the plant also revealed significant inhibition of haemolysis of RBC. Here, the aqueous soluble fraction of bark produced the highest inhibition haemolysis of RBC.

It has been reported that flavonoids exert profound stabilizing effects on lysozomes both in vitro and in vivo experimental animals ${ }^{14}$ while tannins and saponins have the ability to bind cations and other biomolecules and are able to stabilize erythrocyte membrane. ${ }^{15-16}$ The results showed that the extracts were potent on human erythrocyte adequately protecting it against hypotonic solution induced lyses which suggests the presence of flavonoid compounds in this plant. ${ }^{5}$

Bioactive compounds are mostly toxic at higher dose. Thus, in vivo lethality in a simple zoological organism can be used as a convenient monitor for screening and fractionation of crude extracts in the discovery of new bioactive natural products. In the present study, all the crude extracts and the pet-ether, carbon tetrachloride, chloroform, and aqueous soluble fractions of both leaf and bark showed positive results indicating that the test samples are biologically active. Each of the test samples showed different mortality rates at different concentrations. Plotting of $\log$ of concentration versus percent mortality for all test samples showed an approximate linear correlation. From the graphs, the median lethal concentration $\left(\mathrm{LC}_{50}\right.$, the concentration at which $50 \%$ mortality of brine shrimp nauplii occurred) was determined for the samples.

Table 1. Effect of extractives of leaf and bark of $O$. indicum on hypotonic solution induced haemolysis of mice erythrocyte membrane.

\begin{tabular}{lcccc}
\hline \multirow{2}{*}{$\begin{array}{l}\text { Sample } \\
\text { code }\end{array}$} & \multicolumn{2}{c}{$\begin{array}{c}\text { \% Inhibition of } \\
\text { haemolysis }\end{array}$} & \multicolumn{2}{c}{$\begin{array}{c}\text { Cytotoxic activity } \\
\left(\mathrm{LC}_{50} \mu \mathrm{g} / \mathrm{ml}\right)\end{array}$} \\
\cline { 2 - 5 } CME & Leaf & Bark & Leaf & Bark \\
PESF & 67.77 & 61.22 & 17.08 & 12.83 \\
CTSF & 66.66 & 38.88 & 1.81 & 22.27 \\
CSF & 43.33 & 20 & 16.11 & 6.54 \\
AQSF & 72.22 & 50 & 15.03 & 8.4 \\
ASA & 67.89 & 63.33 & 20.93 & 12.03 \\
VS & 82.22 & 82.22 & ND & ND \\
\hline
\end{tabular}

Here, ASA = acetyl salicylic acid, VS = vincristine sulphate, CME = crude methanolic extract; $\mathrm{PESF}=$ petroleum ether soluble fraction; $\mathrm{CTSF}=$ carbon tetrachloride soluble fraction; $\mathrm{CSF}=$ chloroform soluble fraction; AQSF = aqueous soluble fraction of the leaf and bark of methanolic extract of $O$. indicum. ND = not determined

The petroleum ether soluble fraction of crude methanol extract of leaf demonstrated strong cytotoxic activity with $\mathrm{LC}_{50}$ value of $1.81 \mu \mathrm{g} / \mathrm{ml}$ while the crude methanol extract and its carbon tetrachloride, chloroform and aqueous soluble fractions were also moderately cytotoxic with $\mathrm{LC}_{50}$ values of $17.08,16.11,15.03$ and $20.93 \mu \mathrm{g} / \mathrm{ml}$, 
respectively as compared to $0.451 \mu \mathrm{g} / \mathrm{ml}$ produced by vincristine sulphate (Table 1). On the other hand, the carbon tetrachloride and chloroform soluble fractions of bark of $O$. indicum revealed strong cytotoxic activity with $\mathrm{LC}_{50}$ value of 6.54 and $8.4 \mu \mathrm{g} / \mathrm{ml}$, respectively.

Screening for biological activities of the leaf and bark of $O$. indicum reveals that the plant has good potential to be used for the development of lead compounds having different types of biological activities i.e., membrane stabilizing and cytotoxic activities. The petroleum-ether soluble fraction of crude methanol extract of leaf and carbon tetrachloride and chloroform soluble fractions of bark demonstrated strong cytotoxic activity. These observed bioactivities rationalize the traditional uses of the plant as aninflammatory, antimicrobial and anticancer agents. The plant could be subjected for extensive chromatographic separation and purification processes to isolate lead compounds for the discovery of novel therapeutic agents.

\section{REFERENCES}

1. Tiwari, S., Singh, K. and Shah, P. 2007. In vitro propagation of Oroxylum indicum- An endangered medicinal tree. Biotechnology. 6, 299-301.

2. Warrier, P.K., Nambiar, V.P.K. and Ramankutty, C. 1995. Oroxylum indicum. In: A compendium of 500 species, Indian Medicinal Plants, Vol IV. Madras, Orient Longman Ltd.: 186-190.

3. Mao, A.A. 2002. Oroxylum indicum Vent.-A potential anticancer medicinal plant. Indian J. Traditional Knowledge. 1, 17-21.

4. Costa-Lotufo, L., Khan, M., Ather, A., Wilke, D., Jimenez, P., Pessoa, C. and de Moraes, M. 2005. Studies of the anticancer potential of plants used in Bangladeshi folk medicine. J. Ethnopharmacol. 99, 21-30.

5. Chen, L.J., Games, D.E., and Jones, J. 2003. Isolation and identification of four flavonoid constituents from the seeds of Oroxylum indicum by high-speed counter-current chromatography. J. Chromatogr. A 988, 95-105.
6. Nakahara, K., Roy, M.K., Alzoreky, N.S., Na-Thalang, V. and Trakoontivakorn, G. 2002. Inventory of indigenous plants and minor crops in Thailand based on bioactivities, $9^{\text {th }}$ JIRCAS International Symposium-Value addition to Agricultural Product, pp. 135-139.

7. Kalaivani, T. and Mathew, L. 2010. Free radical scavenging activity from leaves of Acacia nilotica (L.) Wild. ex Delile, an Indian medicinal tree. Food Chemical Toxicol. 48, 298305.

8. Cesquini, M., Torsoni, M.A., Stoppa, G.R., Ogo, S.H.T$\mathrm{BOOH}, 2003$. Induced oxidative damage in sickle red blood cells and the role of flavonoids. Biomed. Pharmacotherapy 57, 124-129.

9. Kuddus, M.R., Rumi, F., Kaisar, M. A., Rahman, M.S., Hasan, C.M., Hassan, M.A. and M. A. Rashid 2011. Secondary metabolites from Melocanna Baccifera (Roxb.), Asian J. Chem. 23, 85-88.

10. Sikder, M.A., Saha, R., Rokibuzzaman, M., Sharmin, T., Rashid, R.B., Uddin, M.Z. and Rashid, M.A. 2013. Preliminary biological investigations of Lophopetalum fimbriatum and Calophyllum innophyllum. Bangladesh Pharm. J. 16, 205-209.

11. VanWagenen, B.C., Larsen, R., Cardellina, J.H. II, Ran dazzo, D., Lidert, Z.C. and Swithenbank, C. 1993. Ulosantoin, a potent insecticide from the sponge Ulosa ruetzleri. J. Org. Chem. 58, 335-337.

12. Shinde, U.A., Phadke A.S., Nair A.M., Mungantiwar A.A., Dikshit V.J. and Saraf M.N. 1999. Membrane stabilizing activity- a possible mechanism of action for the antiinflammatory activity of Cedrus deodara wood oil. Fitoterapia 70, 251-257.

13. McLaughlin, J.L., Anderson, J.E. and Rogers, L.L. 1998. The use of biological assays to evaluate botanicals. Drug Infor. J. 32, 513-524.

14. Middleton, J.E. 1996. Biological properties of plant flavonoids: An overview. Int. J. Pharmacognosy. 34, 344348.

15. Oyedapo, O.O. 2001. Biological activity of Plyllanthus amarus extracts on pragrow-Dawley rats. Niger. J. Biochem. Mol. Biol. 16, 83-86.

16. El-Shanbrany, O.A., El-Gindi, O.D., Melek, F.R., AbdelKhalk, SM. and Haggig, M.Y. 1997. Biological properties of saponin mixtures of Fagonia cretica and Fagonia mollis. Fitoterapia LX VIII: 219-222. 